\title{
ENHANCED LANDFILL MINING: KONSEP BARU PENGELOLAAN LANDFILL BERKELANJUTAN
}

\section{Enhanced Landfill Mining: A New Concept of Sustainable Management Landfill}

\author{
Sri Wahyono \\ Pusat Teknologi Lingkungan \\ Badan Pengkajian dan Penerapan Teknologi (BPPT), \\ Jalan M.H. Thamrin No. 8 Jakarta 10340 \\ E-mail : sri.wahyono@bppt.go.id
}

Diterima: 30 Maret 2012; Direvisi: 9 April 2012; Disetujui: 18 April 2012

\begin{abstract}
Enhanced landfill mining (ELFM) is a new concept that integrates recovery of materials and energy in a landfill for sustainability of material and landfill management. The concept integrates a variety of technologies such as excavating, sorting, thermal, transformation and recycling technology. It is also integrated with the non-technical aspects such as regulatory, market, economic, social, and environmental aspects. The concept of ELFM can be an alternative solution for the landfill management problem.
\end{abstract}

Keywords: landfill mining, sustainability

\begin{abstract}
Abstrak
Enhanced landfill mining (ELFM) adalah konsep baru yang terintegrasi tentang recovery material dan energi pada sebuah landfillyang bermanfaat bagi keberlanjutan pengelolaan material dan pengelolaan landfill. Konsep tersebut mengintegrasikan berbagai teknologi seperti teknologi ekskavasi, teknologi pemilahan, teknologi termal, teknologi transformasi dan daur ulang. Hal tersebut juga terintegrasi dengan aspek non teknis seperti aspek regulasi, market, ekonomi, sosial, dan lingkungan. Konsep ELFM menjadi alternatif solusi permasalahan pengelolaan landfill.
\end{abstract}

Kata Kunci: landfill mining, berkelanjutan

\section{PENDAHULUAN}

Tempat Pemrosesan Akhir Sampah (TPA) atau landfill merupakan subsitem yang sangat penting dalam pengelolaan sampah kota. Landfill merupakan tempat berakhirnya sampah setelah proses panjang pengelolaannya yang berawal dari subsistem pewadahan, pengumpulan, pengangkutan, pemilahan, daur ulang hingga pembuangannya. Sampah yang tidak tertangani atau terdaur ulang diangkut dan ditimbun di landfill. Dalam pandangan kegiatan pengelolaan sampah, landfill merupakan ujung akhir sistem. Tidak terbayangkan seandainya suatu kota tanpa landfill. Sampah akan menumpuk di manamana mengakibatkan bau busuk, menyebarnya bibit penyakit, kekumuhan, dan sebagainya.

Sejalan dengan pertumbuhan jumlah timbulan sampah dan rentang waktu kehidupan perkotaan, landfill akan semakin penuh dan daya tampungnya semakin terbatas dan pada akhirnya harus ditutup karena tidak mampu menampung sampah lagi. Seperti umumnya pada saat pengoperasiannya, pada pasca penutupannya juga meninggalkan jejak buruk terhadap lingkungan dan penduduk di sekitarnya misalnya berupa ancaman bahaya longsor tumpukan sampah, ledakan dan kebakaran gas metan, pencemaran air dan tanah, emisi gas rumah kaca, dan sebagainya.

Pencemaran air, tanah dan udara pasca penutupan landfill tidak tertahankan karena pada masa-masa yang lalu umumnya teknis landfilling masihmenganutsistemopen dumping atausampah hanya ditimbun di lahan terbuka tanpa rekayasa teknis yang memungkinkan pencemaran dicegah. Oleh karena itu, banyak terjadi kasus generasi masa kini yang mewarisi beban pencemaran landfill yang diakibatkan oleh kecerobohan para moyangnya dalam mengelola sampah. 
Di sisi lain, pasca penutupan landfill, penduduk perkotaan memerlukan lokasi landfill yang baru untuk membuang padatan sisa peradabannya. Saat ini, untuk menemukan lokasi landfill yang sesuai dengan kriteria teknis dan terhindar dari restriksi masyarakat bukanlah hal yang mudah. Berbagai upaya dilakukan untuk mengatasi masalah tersebut. Salah satu upaya tersebut adalah dengan cara menggunakan kembali landfill yang telah habis masa pakainya.

Upaya penggunaan kembali (reuse) landfill diawali dengan kegiatan ekstraksi gas dan material landfill atau disebut landfill mining. Landfill mining adalah proses mengekstraksi material atau sumber daya alam berbentuk padat dari material limbah yang sebelumnya dibuang dengan cara ditimbun dalam tanah [1]. Pengertian lainnya, landfillmining adalah ekskavasi dan pemindahan material dari landfill untuk tujuan daur ulang, reuse, dan composting [2]. Hal itu termasuk di dalamnya upaya recovery material dan pemrosesannya serta memanfaatkann lahannya sebagai landfill baru.

Landfill mining dimulai tahun 1990-an. Di masa lalu, landfill mining bertujuan terbatas pada rehabilitasi lahan landfill sebagai upaya penanganan pencemaran pasca penutupan landfill $[3,4]$. Pada dekade ini, selain ditujukan untuk rehabilitasi lahan, landfill mining juga ditujukan untuk ekstraksi gas metan, guna ulang lahan landfill, dan menata ulang material.

Saat ini landfill mining diberi pemaknaan baru. Landfill mining bukan dipandang sebagai kegiatan end pipe atau di akhir sistem, tetapi dipandang sebagai kegiatan awal seperti halnya eksplorasi mineral pada bidang pertambangan. Dalam hal ini, landfill mining termasuk dalam kegiatan besar proses recovery material perkotaan atau urban mining. Landfill mining adalah strategi untuk mengembalikan sumberdaya material dan energi dariwarisan sampah masa lampau dalam kerangka efisiensi sumber daya (resource efficiency) [11]. Urban mining sendiri merupakan strategi global dalam pengelolaan material yang berkelanjutan (sustainable materials management) [15].

Konsep landfill mining yang holistik telah dikembangkan oleh sebuah konsorsium pakar lintas disiplin ilmu di Flanders (Belgia) sejak tahun 2008. Konsep tersebut disebut Enhanced landfill mining (ELFM) atau secara harafiah diterjemahkan sebagai landfill mining yang diperluas. ELFM didefinisikan sebagai pengkondisian, ekskavasi dan valorisasi yang aman dan terintegrasi terhadap sampah yang ditimbun (dari masa lalu atau masa depan) baik itu dimanfaatkan sebagai material (waste to material, WtM) maupun sebagai energi (waste to energy, WtE) menggunakan teknologi transformasi yang inovatif serta memperhatikan kriteria sosial dan lingkungan yang ketat.
Berdasarkan definisi tersebut, landfill bukan lagi dipandang sebagai tempat pembuangan akhir tetapi dipandang atau dijadikan sebagai tempat penampungan sementara (temporary storage) [19]. Konsep landfill sebagai penampungan sementara juga bermanfaat untuk memastikan bahwa material pada akhirnya akan di-reuse atau didaur ulang, bukan langsung dihancurkan dengan cara dibakar atau permanen ditimbun.

Di masa depan landfill merupakan lokasi penambangan material yang saat ini belum ekonomis untuk ditambang dengan teknologi saat ini. Konsep tersebut juga memberikan kesadaran kepada pengelola dan operator landfill serta masyarakat bahwa landfill perlu ditambang dikemudian hari. Jadi dalam konsep ELFM, landfill bukan lagi sebagai tempat penimbunan akhir tetapi sebagai tempat penampungan sementara menunggu pengolahannya lebih lanjut.

\section{BAHAN DAN METODE \\ 2.1 Input-Output Material dan Energi dalam Sistem ELFM}

Konsep ELFM mengacu pada hukum termodinamika pertama. Hukum termodinamika pertama, yaitu hukum konservasi energi, menyatakan bahwa jumlah energi dalam alam semesta adalah konstan. Jumlah energi tidak dapat bertambah atau berkurang [8] . Hukum konservasi energi juga berarti konservasi massa atau material. Material dalam sistem tertutup akan tetap konstan sepanjang waktu. Material tidak dapat diciptakan dan dihancurkan, meskipun mungkin berubah dalam ukurannya dan berubah menjadi tipe partikel yang berbeda. Material yang masuk ke dalam suatu sistem tidak dihancurkan melainkan ditransformasikan secara kimiawi menjadi produk lain. Hukum konservasi massa diwujudkan ke dalam prinsip material balance (keseimbangan material) yaitu keseimbangan antara material yang masuk (input) dan keluar (output) dari suatu sistem.

Dalam konsepnya, ELFM adalah sistem yang di dalamnya meliputi berbagai aspek seperti aspek tekonologi, regulasi dan market. Ketiga aspek tersebut menentukan performansi ekonomi dan keberlanjutan ELFM. Aspek teknologi meliputi dua hal pokok yaitu teknologi untuk me-recovery material dan me-recovery energy. Aspek regulasi antara lain meliputi perijinan, subsidi, pajak, dan sebagainya. Sementara itu, aspek market meliputi kebutuhan pasar, harga material, biaya input, dan energi $[5,11]$.

Selain aspek-aspek tersebut, ELFM juga meliputi berbagai aktor seperti pemerintah, swasta kalanganakademisidanlain-lainyangyangmemiliki perspektif dan kepentingan yang berbeda[16].

Aliran material input yang masuk ke dalam 
sistem ELFM meliputi sampah di landfill, biaya modal, tenaga kerja, mineral dan energi. Sementara itu, output-nya berupa output yang diharapkan dan yang tidak diharapkan. Output yang diharapkan berupa material dan energi, sedangkan output yang tidak diharapkan adalah emisi gas dan sisa sampah [5,11]. Emisi gas, sepertiCO2, agartidakmembahayakan lingkungan dikaji untuk disimpan di dalam lapisan bumi [10].

Konsep ELFM memungkin siklus material tertutup seperti halnya recycling terhadap residu proses manufaktur suatu produk dan urban mining terhadap produkyang telahberakhirmasapakainya.

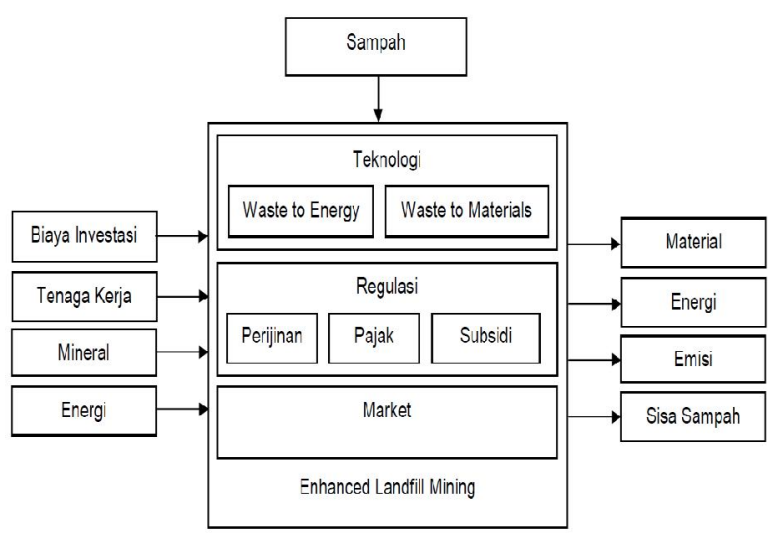

Gambar 1. Input-Output Enhanced landfill mining (Dimodifikasi dari Van Passel et al, 2011) [5,11]

\subsection{Kajian ELFM}

ELFM adalah sebuah konsep baru yang perlu dikaji. Kajian tentang ELFM sedang dilakukan oleh konsorsium para pakar dari berbagai disiplin ilmu di Belgia sejak tahun 2007 dengan nama proyek closing the circle (CtC). Lokasi kajian terletak di landfill REMO, Belgia. Studi diawali dengan pematangan konsep ELFM yang telah selesai pada tahun 2008. Setelah itu dilakukan secara rinci uji valorisasi, perekayasaan, dan elaborasi proyek dalam tahun 2009-2012. Kemudian mulai tahun 2013, studi tersebut masuk ke fase skala pilot. Setelah itu akan dibangun skala penuh plant WtE dan WtM pada tahun 2017. Proyek CtC memerlukan investasi sekitar 230 juta Euro dan akan mempekerjakan 800 orang $[6,7]$.

WtE dan WtM direncanakan akan beroperasi selama 20 tahun. Aplikasi WtE diskenariokan dengan menggunakan teknologi plasma [17]. Energi yang akan dihasilkan diperkirakan sebesar 75 MW - 100 MW dengan teknologi gasifikasi plasma. Carbon dioksida dari WtE akan ditangkap dengan berbagaimetoda. Setelah periode tersebut, landfill akan secara bertahap dikembangkan sebagai taman yang berkelanjutan $[6,7,12]$.

Proyek CtC meliputi rentang studi yang luas yang meliputi aspek teknologi, sosial dan lingkungan [14]. Pertama, dilakukan studi karakterisasi sampah yang digali dari landfill yang bertujuan untuk memverifikasi kualitas data sampah yang tercatat dalam log book seperti data tentang jenis, jumlah, dan potensi sampah untuk di recovery material dan energinya $[6,7,12]$. Studi tentang komposisi dan karakteristik sampah yang digali dari landfill juga dilakukaN oleh kelompok riset lain seperti di New Jersey dengan hasil riset yang komprehensif [23].

Kedua, studi validasi terhadap material yang digali dan teknologi valorisasi energi. Material yang digali diproses melalui beberapa tahap yaitu screening, wind shifter, washing, dense medium separator, magnet, eddy current dan shredder. Studi serupa juga telah dilakukan oleh beberapa negara, misalnya Finlandia, India, dan Jerman $[20,21,22]$. Residu material diproses menjadi RDF sebagai bahan bakar gasifikasi plasma.

Ketiga, analisis konservasi alam, mengkaji dampak lingkungan dan mempertimbangkan integrasi lokasinya dengan konservasi alam. ELFM berdampak positif pada lingkungan karena mereklamasi lahan dan merestorasi lokasi dan juga mereduksi penggunaan bahan bakar fosil.

Keempat, melakukan studi carbon footprint sebagai studi ekonomi lingkungan untuk mendemonstrasikan keuntungan landfill mining dengan skenario tidak melakukan apa-apa. Untuk memproduksi energi dan material dalam jumlah yang sama total level gas rumah kaca yang diemisikan dari skenario CtC secara signifikan lebih rendah daripada tidak dilakukan apa-apa: 5,3 juta ton $\mathrm{CO}_{2}$ e berbanding dengan 6,3 juta ton $\mathrm{CO}_{2} \mathrm{e}$, mereduksi $15 \%$ emisi GRK $[6,7]$.

Studi tentang konsep, sosial, dan hukum juga dilakukan. Berdasarkan studi ekonomi, sosial dan lingkungan, konsep ELFM sangat bermanfaat. Sebagaimana sumber daya primer menjadi semakin langka dan biaya eksternal sumberdaya primer diinternalisasikan, keekonomian ELFM menjadi layak. Secara teknologi, teknik pemisahan dan teknologi WtE dan WtM adalah faktor kunci. Kebijakan strategis juga diperlukan untuk menghilangkan barier non teknis.

\section{HASIL DAN PEMBAHASAN}

\subsection{Strategi Teknis ELFM}

Strategi teknis ELFM tergantung dari parameter instrinsik dan ekstrinsik landfill. Yang dimaksud dengan paramaeter intrinsik adalah kondisi internal landfill seperti luas, lokasi, umur, tipe, dan komposisi sampahnya. Sementara itu, parameter ekstrinsik adalah kondisi eksternal seperti ketersediaan teknologi yang cocok, batasan ekonomi dan kondisi sosial [7].

Penambangan landfill meliputi dua kategori 
yaitu in-situ dan ex-situ landfill mining [7]. In situ landfill mining adalah aktivitas pengembalian sumberdaya tanpa melakukan ekskavasi seperti ekstraksi landfill gas untuk energi. Hal ini cocok dilakukan untuk landfill yang banyak mengandung sampah organik domestik. Sementara itu, ex -situ landfill mining merujuk pada aktivitas pengembalian sumberdaya dengan melakukan ekskavasi sebagian atau menyeluruh material landfill untuk diolah lebih lanjut. Hal tersebut cocok untuk landfill industri atau campuran domestik dan industri yang banyak mengandung logam, plastik, kaca, dan sebagainya.

Strategi landfillmining dalam proyekCtC dimulai dengan mengekstraksi landfill gas. Material yang telah siap didaur ulang menjadi sumberdaya kembali. Kompos atau hasil dekomposisi material organik yang telah stabil termasuk material jenis ini. Kompos dapat dimanfaatkan sebagai soil conditioner lanskap perkotaan, lahan kritis, areal reboisasi, dan sebagainya [24].

Material yang diproses secara termal (seperti fraksi kayu, tekstil, karet, dan fraksi lembut organik) selain menghasilkan energi juga menghasilkan abu, slag atau plasmarock yang dapat dimanfaatkan sebagai bahan bangunan.

Sementara itu, residu material yang belum dapat dimanfaatkan dikirim kembali ke landfill yang telah difungsikan sebagai penampungan sementara untuk suatu saat, dimasa depan, didaurulang ketika teknologi transformasi telah ditemukan atau secara ekonomi layak untuk diolah.

Bahan yang secara langsung dapat didaur ulang seperti material logam besi dan non besi, plastik, beling, dan sebagainya. Material tersebut merupakan sumberdaya sekunder yang bermanfaat untuk mensubstitusi sumber daya primer. Hal tersebut dikategorikan sebagai waste to material (dari limbah menjadi sumberdaya material).

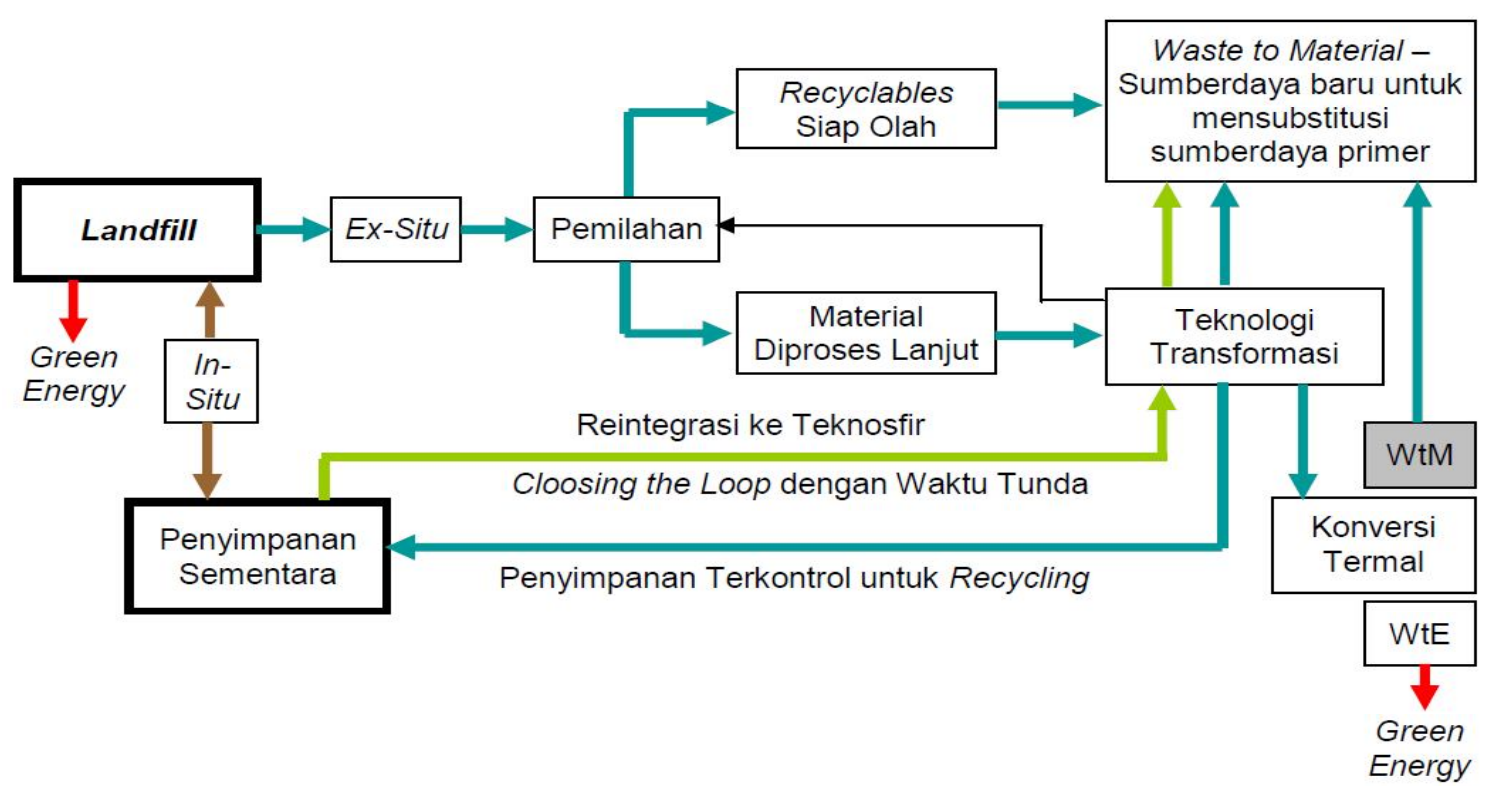

Gambar 2. Konsep Integrasi ELFM (dimodifikasi dari Laevers et al, 2011)[6]

Material lainnya yang tidak dapat langsung dimanfaatkan sebagai sumberdaya sekunder diproses lebih lanjut dengan teknologi transfomasi. Dari proses ini akan didapatkan material siap di daur ulang, siap dikonversikan secara termal menjadi energi (waste to energy), kompos, dan residu material yang secara teknis saat ini belum bisa di-recovery atau kelayakan ekonominya belum sesuai dengan yang diharapkan.

\subsection{Manfaat-Biaya ELFM}

Dari uraian di atas, konsep ELFM memiliki beberapa manfaat internal seperti lahan yang diperbaiki dapat digunakan untuk keperluan lain, meningkatkan kapasitas landfill, menyediakan lahan baru landfill, mencegah atau mereduksi biaya penutupan landfill dan pemeliharaannya pasca penutupan, serta revenue dari recyclable material seperti tanah, logam, plastik, kaca, kayu, dan sebagaimana. Sedangkan manfaat ekternalnya meliputi reduksi emisi gas rumah kaca, meningkatkan kembali nilai lahan di sekitar landfill, reduksi pencemaran air tanah dan sebagainya.

Terkait dengan biaya, pembiayaan ELFM tergantung dari beberapa hal seperti karakteristik landfill (material yang ditimbun, komposisi sampah, praktek penimbunan, usia dan kedalaman timbunan, rasio tanah penutup), ekonomi regional (nilai tanah, biaya material penutup dan monitoring), keberadaan 
material bahan beracun dan berbahaya (B3), serta ukuran dan volume landfill [2].

Menurut studi analisis manfaat-biaya (cost benefit analysis) ELFM untuk melakukan kegiatan ELFM terhadap TPA dengan luas $2.000 \mathrm{Ha}$ diperlukan biaya sebesar 12.779.680.000 Euro [5]. Sementara itu manfaat yang didapatkan berupa material yang berhasil direcovery senilai 1.534.382.080 Euro, energi yang di-recovery senilai 1.534.382.080 Euro, reklamasi landfill senilai 1.368.000.000, dan reduksi carbon footprint senilai 256.650.240 Euro. Dari nilai manfaat -biaya didapatkan selisih sebesar 317.134.876 Euro. Dengan demikian, ELFM menurut studi tersebut secara ekonomi menguntungkan.

\subsection{Konsep Penerapan ELFM di Indonesia}

Di Indonesia, seperti halnya di negara sedang berkembang lainnya, level pengelolaan akhir sampah masih berkutat pada upaya peningkatan sistem landfill yang tadinya open dumping menjadi sistem yang saniter yaitu sanitarylandfill. Hal tersebut ditegaskan dalam UU No. 18 Tahun 2008 yang tersirat dalam pasalnya bahwa sistem open sejak tahun 2013 sudah dilarang dioperasikan karena tidak bersahabat dengan lingkungan dan harus digantikan dengan sistem yang saniter. Hal ini berbeda dengan di negara -negara maju, di mana tahap pengelolaan akhir sampahnya setahap lebih maju yaitu umumnya sudah menggunakan sistem yang saniter yang dapat meminimalisir terjadinya pencemaran lingkungan akibat lindi dan emisi landfill gas.

Di Indonesia, transisi aplikasi sanitary landfill dari open dumping menuju sanitary landfill berupa revitalisasisistemopen dumping menjadicontrolled landfill. Hal tersebut berlaku bagi kota kecil dan sedang. Sementara itu, dalam kebijakannya secara nasional, pemerintah kabupaten/kota secara bersama dapat mengaplikasikan sanitary landfill regional yang pembiayaan disain dan kontruksinya ditanggung oleh pemerintah pusat.

Proses revitalisasi landfill yang dilakukan oleh pemerintah daerah melibatkan operasi ekskavasi timbunan sampah. Namun, proses tersebut umumnya belum dipandang sebagai landfill mining yang memiliki pengertian pengekstrasian material yang ditimbun dengan tujuan pengembalian material dan energi. Ekskavasi lebih bertujuan untuk proses engineering perbaikan landfill.

Hal tersebut masih jauh dari pengertian sistem landfill mining. Secara sistem, landfill mining meliputi berbagai komponen seperti komponen teknologi, regulasi dan pasar. Ketiga komponen tersebut menentukan performansi ekonomi dan keberlanjutan landfill mining. Komponen teknologi meliputi dua hal pokok yaitu teknologi untuk mengembalikan material dan energi.
Aspek regulasi antara lain meliputi perijinan, subsidi, pajak, dan sebagainya. Sementara itu, aspek market meliputi kebutuhan pasar, harga material, biaya input, dan energi [5].

Jadi di Indonesia, seperti di negara-negara maju pada tahun 1990-an, landfill mining bertujuan terbatas pada revitalisasi atau rehabilitasi landfill sebagai upaya penanganan pencemaran yang ditimbulkannya [3,4]. Selain itu juga sebagai upaya memperpanjang umur landfill yang berarti pula mereduksi kebutuhan lahan akan landfill $[9,13]$.

Dari sisi konsep, di Indonesia, penggunaan kembali TPA dikenal dengan istilah reusable sanitary landfill. Istilah tersebut disosialisasikan sejak pertengahan tahun 2000-an oleh BPPT yang kemudian ditindaklanjuti dengan penelitian terhadap dua demo plant landfill di TPA Regional Banglet, Bali. Reusable sanitary landfill adalah pengkondisian sanitary landfill dengan resirkulasi lindi dan pengendalian gas untuk mempercepat dekomposisi sampah dalam serial sel landfill yang kemudian ditambang secara bergiliran untuk dipakai kembali menjadi landfill kembali [25].

Studi tentang landfill mining pernah dilakukan di beberapa landfill yaitu TPABantargebang (Bekasi), TPA Maminasata (Makasar), dan TPA Leuwigajah (Bandung) oleh ITB, BPPT, dan lembaga riset dari Australia. Kompos yang umumnya mengandung logam berat diatas ambang batas sehingga tidak cocok untuk tanaman pangan. Sementara itu, bahan yang didapat kualitasnya rendah sehingga kurang diminati pasar.

Penggunaan kembali landfill melalui landfill mining sangat besar pengaruhnya pada keberlanjutan pengelolaan sampah karena untuk mencari lokasi TPA yang baru sangatlah sulit akibat penolakan masyarakat dan kelangkaan lahan di perkotaan [26].

\section{KESIMPULAN}

Enhanced landfill mining (ELFM) adalah konsep baru yang terintegrasi tentang recovery material dan energi pada sebuah landfill yang bermanfaat bagi keberlanjutan pengelolaan material dan pengelolaan landfill. Konsep tersebut mengintegrasikan berbagai teknologi seperti teknologi ekskavasi, teknologi pemilahan, teknologi termal, teknologi transformasi dan daur ulang. Terintegrasi dengan aspek non teknis juga seperti aspek regulasi, pasar, ekonomi, sosial, dan lingkungan. Saat ini konsep tersebut masih dalam tahap pengujian. Diharapkan, konsep ELFM dapat menjadi aplikatif sebagai solusi bagi keberlanjutan pengelolaan landfill atau persampahan dan keberlanjutan pengelolaan material di wilayah perkotaan. 


\section{DAFTAR PUSTAKA}

1. Krook, J., Svensson, N., dan Eklund, M., (2012). Waste Management. 32, 513-520

2. Hogland, W. (2011). Landfill Mining/Mining pa deponi. Miljoringen nettverk for forurenset grunn og sedimenter.

3. Prechthai, T., Padmasri, M., dan Visvanathan, C. (2008). Resources, Conservation and Recycling, 53 , p. $70-78$.

4. Van der Zee, D.J., Achterkamp, M.C., dan de Visser, B.J., (2004). Waste Management, 24 (8) (2004), p. 795-804.

5. Van Passel, S., De Gheldere, S., Dubois, M., Eyckmans, J., Vdan an Acker, K. (2010). Exploring the Socio-Economics of Enhanced landfill mining. ELFM Symposium 2010.

6. Laevers, P., Tielemans, Y., Jones, P.T., Geysen, D., Quaghebeur, M., dan Devocht, A. (2011). Closing the Circle: Enhanced landfill mining. Waste management World March-Apr i I 2012.

7. Jones, P.T., Geysen, D., Tielemans, Y., Pontikes, Y., Blanpain, B., Mishra, B., dan Apelian, D. (2012). Closing Material Loops: the Enhanced landfill mining Concept. JOM DOI: 10.1007/s11837-012-0378-1 2012 TMS

8. Kristianto, Philip. (2002). Ekologi Industri. Andi Offset, Yogyakarta

9. Guerriero, J. (1996). Status Of Landfill Reclamation And Its Applicability to Solid Waste. Management.
Proceedings of the 17th Biennial Waste Processing Conference ASME 1996

10. Laenen, B dan Van Tongeren, P. (2012). Landfill Mining and $\mathrm{CO} 2$ Storage in Unmineable Coal Seams - Assessing the Feasibility for the Campine Basin (Northern Belgium). Environment, Nature and Energy department of the Flemish government, Flemish Government.

11. Van Gerven, T., Geysen, D., Pontikes, Y., Cizer, O., Mertens, G., Elsen, J., Van Balen, K., Jones, P.T., Blanpain, B. (2011). An Integrated Materials Valorisation Scheme for Enhanced landfill mining. ELFM Symposium.

12. Laevers, P. dan Tielemans, Y. (2010). Closing the Circle: an Enhanced landfill Mining Case Study Enhanced landfill mining. ELFM Symposium 2010.

13. Nelson, H. (1994). Landfill Reclamation Strategies. BioCycle, October 1994

14. Paredis, E, Tempst, W. dan Moyersoen, J. 2010. Developing Enhanced Landfill Mining as a transition experiment: context, framing, methodology, questions. ELFM Symposium (2010).

15. Jones, P., Geysen, D., Rossy, A., Bienge, K. (2010). Enhanced Landfill Mining (ELFM) and Enhanced Waste Management (EWM): essential components for the transition to Sustainable Materials Management (SMM). ELFM Symposium 2010.

16. Craps, M, dan Sips, K. (2010). Enhanced Landfill Mining as a governance challenge: managing 